\title{
Materials Research Society of Japan Hosts Annual Meetings, Ad Hoc Lectures, and Symposia
}

The Advanced Materials Science and Engineering Society (AMSES), founded on March 16, 1989, changed its name to the Materials Research Society of Japan (MRSJ) in December 1990. Each year since, MRS$\mathrm{J}$ has sponsored an Annual Meeting in December and a Summer Meeting in July. Numerous other ad hoc lectures and symposia occur throughout the year. The bimonthly newsletter MRS-J News, written mostly in Japanese, covers news about MRS-J, MRS, and the International Union of Materials Research Societies (IUMRS) and features a conference calendar.

\section{Meetings}

The two-day 1990 Annual Meeting had two concurrent symposia, one on advanced materials chaired by M. Doyama, S. Sōmiya, and M. Hasegawa and another on ceramics chaired by $\mathrm{H}$. Kawazoe, $\mathrm{H}$. Imagawa, K. Arai, and H. Hosono.

The symposium on advanced materials was cosponsored by Kanagawa Academy of Science and Technology and Kanagawa Science Park and consisted of 11 papers presented plus 71 posters.

The symposium on ceramics was cosponsored by New Glass Forum, Asahi Glass Foundation, and Nippon Sheet Glass Foundation. The symposium was comprised of six sessions: Imperfections in Ultrathin Amorphous $\mathrm{SiO}_{2}$ Films, Optical Response and Sol-Gel Processes, Defects and Ion Implantation, Physical Properties and Hydrogen Related Species, and Defects and Imperfections 1 and 2.

The Summer Meeting, held July 11, 1991 in Kawasaki, Japan, covered the development of opto-bio materials and $\mathrm{Al}_{2} \mathrm{O}_{3}$ and aluminum compounds.

The 1991 Annual Meeting was held De- cember 12-13 in Kawasaki, Japan. Special lectures were given by Kin-ichiro Miura on bioscience and by Toshio Nishi on high polymers. The topics for this meeting were: Advanced Materials chaired by M. Doyama, S. Sōmiya, and M. Hasegawa; Ceramic Actuators chaired by K. Uchino; and Computer Applications to Materials Science and Engineering chaired by $M$. Doyama. The Symposium on Ceramic Actuators was co-sponsored by the Japan Technology Transfer Association and the Symposium on Computer Applications was co-sponsored by a Grant-in-Aid from the Ministry of Education, Science and Culture.

\section{Ad Hoc Meetings}

MRS-J holds numerous one-day ad hoc subcommittee meetings on advanced materials, mostly focusing on ceramics. Specific materials and topics discussed so far include aluminum nitride, aluminum oxide, zirconia, zinc oxide, ceramic powders, analysis, synthesis, processing, and electronic and optical sensors. Some symposia were sponsored by the Asahi Glass Foundation and the Nippon Sheet Glass Foundation. On October 15, 1991, "Materials Fountainhead for New Technology and New Science," presented by Rustum Roy, was co-sponsored by the National Academy of Science.

There is an established subcommittee on hydrothermal reactions, and a new subcommittee on computer applications to materials and molecular science and engineering is being started.

\section{Honorary Members}

Since December 1990, MRS-J has chosen 15 honorary members: R.P.H. Chang
(USA), D.S. Yan (China), O.C.C. Lin (Taiwan, China), M.J. Murry (Australia), Min Che Chon (Korea), C.N.R. Rao (India), Byong Sik Jeon (Korea), Kee Hyong Kin (Korea), Rustum Roy (USA), E.F. Osborn (USA), J.A. Pask (USA), W.D. Kingery (USA), E. Matijevic (USA), G. Petzow (Germany), and L.E. Cross (USA).

\section{Future Events}

Advanced Materials: (March 13, 1992) the Role of Submicron-Sized Particulates in Preparing Photonic Materials, chaired by S. Sōmiya. Guest speaker will be J.B. MacChesney of AT\&T Bell Laboratories. Minoru Watanabe, Sumitomo Electric Industries Co., Ltd., will speak on recent developments in optical fiber technology.

Summer Meetings:

July 9-10, 1992, Kawasaki, Japan, featuring symposia on aluminum and aluminum composites and zirconia ceramics.

July 8-9, 1993, location to be announced.

\section{Annual Meetings:}

December 10-11, 1992, Kawasaki, Japan, featuring symposia on advanced materials, fracture of materials, etc.

December 9-10, 1993, location to be announced.

For more information about MRS-J and its activities, write to: MRS-J, c/o KSP (Kanagawa Science Park), 304, 100-1 Sakato Takatsu-ku Kawasaki 213 Japan; phone 81-44-819-2001; fax 81-44-819-2009.

\section{Executive Officers}

President: Prof. Masaki Hasegawa

Vice Presidents: Prof. Masao Doyama and Prof. Shigeyuki Sōmiya

Secretary and Treasurer: Yoshitaka Agata

\section{E-MRS, ICEM ' 92 Offer Joint Program Under Auspices of IUMRS}

The European Materials Research Society's 1992 Spring Meeting and the International Conference on Electronic Materials have joined forces to share both the technical program and venue for this year's meeting, June 2 -5, at the Council of Europe and European Parliament facilities in Strasbourg. The combined conference is being organized by E-MRS under the auspices of the International Union of Materials Research Societies (IUMRS). Conference
Chairs G. Crean, Y. Nissim, and M. Stuke along with a 20 -member International Organizing Committee are in the process of preparing the event.

The program features six symposia, a joint session, poster sessions, and an equipment exhibit.

Contact the symposium chairs for information about a specific symposium. For general information about the E-MRS/ ICEM conference, contact the conference secretary, P. Siffert, E-MRS Spring Meeting/ICEM '92, B.P. 20, 67037, Strasbourg Cedex, France; phone (33) 88-28-6543; fax (33) 88-28-09-90.

\section{Symposium A: SiGe-Based Technologies}

This two and one-half day symposium will deal with the preparation of silicon germanium microstructures, their physical, chemical and electrical characteriza- 
tion, and device processing and applications. A special session on ultrathin $\mathrm{Si} /$ Ge superlattices is planned.

Chairs: E. Kasper, Daimler-Benz A.G., Germany, phone (49) 731-505-2039, fax (49) 731-505-4102; Y. Shiraki, RCAST, Japan, phone (81) 3-3481-4428, fax (81) 3-34855135; T.P. Pearsall, University of Washington, USA, phone (1) 206-543-2600, fax (1) 206-543-3100.

\section{Symposium B: Laser, Lamp, and Synchrotron-Assisted Materials Surface Processing}

This four-day symposium will cover all aspects of photon-assisted materials surface processing, from basic studies to novel phenomena for applications and devices. Surface, interface and thin film reactions of dielectrics, semiconducotrs and superconductors, metals, organic and biological materials will be emphasized interms of fundamental understanding and assessing the criteria for future practical applications.

Chairs: E.E. Marinero, IBM Almaden Research Labs, USA, phone (1) 408-9273025; fax (1) 408-927-2077; I. Nishiyama, NEC Opto-Electronics, Japan, phone (81) 298-501169 (or 11), fax (81) 298-566140 (or 31); M. Stuke, Max-Planck-Institut, Germany, phone (49) 551-201-338, fax (49) 551201-330.

\section{Symposium C: Chemistry for Electronic Materials}

This four-day symposium will cover chemistry aspects for all kinds of materials processing used for electronic applications, e.g., Si, III-V compounds, superconductors, and metallization materials. New precursors are of special interest, and presentations will span basic research for fundamental understanding, engineering problems, and future aspects.

Chairs: Y. Pauleau, Inst. National Polytechnique de Grenoble, France, phone (33) 76-88-59-62, fax (33) 76-88-51-30; G. Wahl, Inst. für Oberlachentechnik und Plasmatechnische, Germany, phone (49) 531-3919401, fax (49) 531-391-9400, K.F. Jensen, MTT, USA, phone (1) 617-253-4589, fax (1) 617-253-9695; T. Hirai, Tohoku University, Japan, phone (81) 22-227-6200, fax (81) 22215-2107.

\section{Symposium D: Diagnostic Techniques for Semiconductor Materials Analysis and Fabrication Process Control}

This symposium aims to bring together researchers working in all areas of semiconductor materials and process characterization. Both basic studies and applications will be highlighted.
Chairs: G.M. Crean, National Microelectronics Research Center, Ireland, phone (353) 21-27-68-71, fax (353) 21-27-02-71; M. Kashiwagi, Toshiba Corporation, Japan, phone (81) 44-549-2317, fax (81) 44-5492267; R. Stuck, Centre de Recherches Nucleaires, France, phone (33) 88-28-65-43, fax (33) 88-28-09-90; J. Woollam, University of Nebraska, USA, phone (1) 402-472-1964, fax (1) 402-472-7987.

\section{Symposium E. Synthetic Materials for Nonlinear Optics and Electronics}

This four-day symposium aims to cover the emerging class of unconventional electronic materials based on organic FET molecules and polymers. General topics include design and synthesis of new materials, characterization, processing, and device applications.

Chairs: C. Taliani, CNR, Italy, phone (39) 51-28-70-02, fax (39) 51-22-50-31; Z.V. Vardeny, University of Utah, USA, phone (1) 801-581-8372, fax (1) 801-581-4801; Y. Maruyama, Institute of Molecular Science, Japan, phone (81) 564-55-7410, fax (81) 564-54-2254.

\section{Symposium F: New Aspects of the Growth, Characterization, and Applications of CdTe and Related Cd-Rich Alloys}

This three-day symposium will provide the opportunity to review research devoted to $\mathrm{CdTe}$ and related Cd-rich alloys during the last decade since $\mathrm{K}$. Zanio's monograph. It will cover the most recent aspects, ranging from basic studies to novel applications.

Chairs: R. Triboulet, CNRS, France, phone (33) 1-45-07-50-88, fax (33) 1-45-0758-99; W.R. Wilcox, Charkson University, USA, phone (1) 315-268-6446, fax (1) 315268-3841; O. Oda, Nippon Mining Co., Japan, phone (81) 484-33-2051, fax (81) 484-45-5400.

\section{Joint Session on Single-Chamber Processing: Requirements and Challenges}

This joint session will explore the general aspects and background of integrated processing and present reports on the status of the technology, the design concepts, and relevant equipment. Specific process modules such as deposition chambers, annealing or etching reactors will also be reviewed. Standardization of this equipment will be addressed.

Chairs: Y.I. Nissim, CNET, France, phone (33) 1-42-31-73-19, fax (33) 1-42-5349-30; A. Katz, AT\&T Bell Laboratories, USA, phone (1) 908-582-2261, fax (1) 908582-4347.

\section{ICAM '93 Planned for Tokyo}

The Third International Conference on Advanced Materials (ICAM '93) will be held in Tokyo, Japan, August 31 to September 4, 1993. The ICAM '93 Organizing Committee is being joined in its efforts by MRS-Japan and the International Union of Materials Research Societies. Support is coming from Nikkan Kogyo Shimbun, Ltd.

Just as the first and second conferences (1988 in Tokyo and 1991 in Strasbourg), this conference will cover the entire field of advanced materials with a full complement of symposia. For more information, contact: ICAM'93, clo Nikkan Kogyo Shimbun, Ltd., Business Bureau, 8-10, Kudan-Kita 1Chome, Chiyoda-ku, Tokyo 102, Japan; phone 81-3-3222-7162; fax 81-3-3221-7137.

ICAM '93 Chairs: Masao Doyama, Masaki Hasegawa, Shigeyuki Sōmiya, and Shigehiko Yamada.

Tentative List of Symposia: Composites; Glassy Materials; Powder Preparation; Computer Applications in Materials Science and Engineering; Superplastic Phenomena in Ceramics, Intermetallics, and Composites; Materials Interconnection-A Novel Approach to Functional Joining for Dissimilarity Considerations; Corrosion/ Coating of Advanced Materials; Shape Memory Materials; Hydrogen Absorbing Materials and Hydride Batteries; Structural Ceramics; Development of Environmentally Conscious Materials; Rare-Earth Iron-Based Permanent Magnet Materials; $\mathrm{C}_{60}$ and Related Materials; Biomaterials; Catalytic Materials; Advanced Processing; Ordered Polymers; Photo- and ElectroResponsive Materials; Electronic Materials; Biosensors; Materials Synthesis and Modification by Ion Beams and/or Laser Beams; Materials for Information Storage Media; Fabrication of Silicon-Based Ceramics; Frontiers of Materials Science and Engineering; Diamond and Related Materials; Gradient Materials; Superconducting Materials; Grain Boundaries; Nanophase Materials; Superlattices; Surfaces and Interfaces; Ferro-electric Thin Films; Construction and Functions of Organic Thin Films; Materials for Bioscience and Biotechnology; Microgravity and $\mathrm{Ma}$ terials.

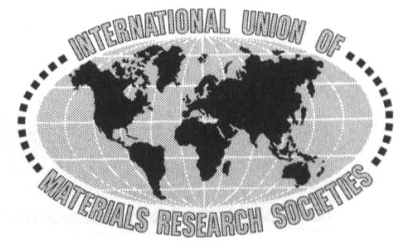

